\title{
Clinico-epidemiological profile of hemophilia with special reference to development of inhibitors in Indian scenario: a crosses sectional study at tertiary care centre in north India
}

\author{
Ram Sunder Sharma*, Arun Kumar Arya, Yashwant Kumar Rao
}

Department of Pediatrics, GSVM Medical College, Kanpur, UP, India

Received: 13 April 2016

Accepted: 09 May 2016

*Correspondence:

Dr. Ram Sunder Sharma,

E-mail: dr.ramsundersharma@gmail.com

Copyright: () the author(s), publisher and licensee Medip Academy. This is an open-access article distributed under the terms of the Creative Commons Attribution Non-Commercial License, which permits unrestricted non-commercial use, distribution, and reproduction in any medium, provided the original work is properly cited.

\section{ABSTRACT}

Background: Development of inhibitors is becoming a great challenge to clinicians in treating patients of Hemophilia. It is one of the most important complication affecting quality of life of patients and cost of treatment. The objective of the study was to study the prevalence of inhibitors in Hemophilia, its clinical presentation and factors (no. of exposure days, age of 1st presentation) affecting the development of inhibitors in Indian context.

Methods: We conducted a cross-sectional study on 54 patients of severe Hemophilia admitted in our hospital. We assessed their treatment data and screened their samples for inhibitors by mixing study and confirmation done by Bethesda assay.

Results: Out of 54 patients of severe Hemophilia 49 patients was of Hemophilia A and 5 of Hemophilia B. Out of these 49 patients 5 patients $(10.2 \%)$ was positive for inhibitors. None of the HB is positive. Out of these 4 patients $(80 \%)$ presented in their infancy. All patients had 20-50 exposure days. 24\% patients had $>50$ exposure days, none of these develop inhibitor. Out of these 5 positive patients $4(80 \%)$ were low responders and 1 patient $(20 \%)$ was high responder.

Conclusions: In our study prevalence of inhibitor development is less compared to other western studies. This finding might be due to delayed initiation of factor concentrate treatment. In our study due cost of treatment bleeding prophylaxis is not given; only palliative treatment is available in our hospital. But considering small sample size and absence of genetic factors study it needs further study before reaching a final conclusion.

Keywords: Hemophilia, India, Inhibitors

\section{INTRODUCTION}

Hemophilia A (factor VIII deficiency) and Hemophilia B (factor IX deficiency) are the most common and serious congenital coagulation factor deficiencies caused by deficiency of coagulation factor VIII and IX respectively. ${ }^{1}$ Both are $\mathrm{X}$ linked diseases. These factors take part in the intrinsic pathway of blood coagulation

Treatment modalities available for haemophilic patients are factor concentrates (treatment of choice), Cryoprecipitate and fresh frozen plasma (FFP).
Inhibitors are a serious medical problem that can occur when a person with Hemophilia has an immune response to treatment with clotting factor concentrates. An inhibitor is a polyclonal high-affinity immunoglobulin $G$ $(\mathrm{IgG})$ that is directed against the FVIII protein. IgG4 antibodies are predominant and do not fix complement. The formation of a FVIII inhibitor is a T-cell dependent event. $^{2}$

There are many factors affecting inhibitor development. It has been shown repeatedly that disease severity, major FVIII gene defects, family history, and non-Caucasian 
race are major risk factors for inhibitor development. Inhibitors tend to develop within the first 10 exposure days (defined as a 24-hour period during which one or more exposures to FVIII therapy was recorded) and rarely develop after 50 exposure days. ${ }^{3}$

There are some other incompletely understood factors which promotes inhibitor formation such as Source of factor VIII: plasma-derived versus recombinant factor products, early prophylaxis: to prevent inhibitor formation. Treatment-related risk factors that have been postulated include age at first exposure, the intensity of the first exposure, 'danger signals', prophylaxis, and the type of FVIII product (recombinant versus plasma derived). ${ }^{2}$

The management of persons with inhibitors and inhibitors comprises several approaches involving prompt treatment of bleeding episodes, managing its complications, preventing bleeds, and conserving and restoring joint function. The ultimate goal of treating $\mathrm{PWH}$ and inhibitors is to permanently eradicate inhibitors via immune tolerance therapy (ITT), and the same therapy has been indicated for high-responder patients in developed countries. However, ITT is still not feasible in most centres in India because of prohibitive cost and logistics constraints. ${ }^{4}$

Other therapies available are High-dose factor concentrates, bypassing agents and immunoadsorption. In the case of failure of bypassing agents to control bleeding, immunoadsorption may temporarily reduce the inhibitor titre in high-responder inhibitor patients, enabling effective replacement therapy with factor concentrates. Rituximab and plasmapheresis may be helpful in resistant cases. ${ }^{5}$

\section{METHODS}

A Cross sectional study was carried out at Hemophilia treatment centre, children hospital G.S.V.M. medical college, Kanpur, Uttar Pradesh (India) which is a tertiary care hospital.

The study group consists of 54 diagnosed cases of Pediatric age group (0-18years) having severe Hemophilia admitted in Hemophilia treatment centre children hospital GSVM Medical College during January 2012 to July 2013. All of these patients were treated by recombinant factor concentrates during study period.

\section{Inclusion criteria}

All patients attending hemophilia treatment centre for factor replacement therapy.

\section{Methodology}

On a specified day all registered patients of Hemophilia were called and blood samples were collected from all patients for detection of development of factor inhibitors and their treatment record till date was collected. 10 c.c. bloods was collected in two trisodium citrate vacutainers. Then sample was centrifuged at 4000-5000 rpm for 20 minutes, at $4^{0} \mathrm{C}$. Then 4 aliquots of 500 micro litter plasma each, was prepared. The plasma samples were labelled and immediately stored at $-40^{\circ} \mathrm{C}$. Within 2 days samples were transported to National Institute of Immunohematology (ICMR) Mumbai at $-40^{\circ} \mathrm{C}$.

Investigations done were - Screening coagulation tests (PT, APTT), Factor VIII and IX clot based assay. Screening for inhibitors done by plasma mixing test. This test was performed by normal plasma and test plasma incubated for $120 \mathrm{~min}$. aPTT was performed before and after incubating the samples. If positive, quantitative assessment done by Bethesda assay. In this test serial dilutions of test plasma were used and residual factor activity was measured by mixing with normal pooled plasma. A VWF antigen assay - done by ELISA method by using Standard 96-well plate which was are coated with an anti-human VWF antibody.

HIV assay and HBsAg tests were done at Blood Bank Medical College, Kanpur, UP, India by ELISA method.

\section{RESULTS}

This study was carried out to know the Prevalence of inhibitors in patients with Hemophilia $\mathrm{A}$ and $\mathrm{B}$, to identify the risk factors for development of inhibitors. We have drawn the following results from this study.

Table 1: Bleeding frequency per year.

\begin{tabular}{|lll|}
\hline Frequency per year & Cases & $\%$ \\
\hline $1-10$ & 9 & 16.6 \\
\hline $11-15$ & 38 & 70.4 \\
\hline$>15$ & 7 & 13 \\
\hline Total & 54 & 100 \\
\hline
\end{tabular}

Table 2: Most common site of bleeding.

\begin{tabular}{|lll|}
\hline Site & No. of Cases & $\%$ \\
\hline Knee joint & 29 & 53.7 \\
\hline Soft tissue & 9 & 16.6 \\
\hline Elbow joint & 5 & 9.40 \\
\hline Gum & 4 & 7.40 \\
\hline Ankle joint & 3 & 5.5 \\
\hline Hip joint & 2 & 3.7 \\
\hline$>1$ joint & 2 & 3.7 \\
\hline Total & 54 & 100 \\
\hline
\end{tabular}

Table 1 shows that majority of patients $(70.4 \%)$ presented to us had bleeding frequency of 11-15 per year. Frequency of bleeding in majority of patients was 11-15 per year. But patients did not have factor replacement each time might be because minor bleeding episodes were not reported immediately and unavailability of 
factor concentrate each and every time in Indian context (Table 1).

The above table shows that majority of patients $(70.4 \%)$ presented to us had bleeding frequency of 11-15 per year.

Table 2 shows that knee is most common site of repetitive bleeding and hemarthrosis is most common presenting symptom. Hemarthrosis was commonest complication affecting $79.6 \%$ patients. Most common involved joint was knee joint (53.7\%) (Table 2).

Table 3: Clinical profile and risk factors in inhibitor positive patents.

\begin{tabular}{|lll|}
\hline Freq./year & $\begin{array}{l}\text { Age at } \text { 1 }^{\text {st }} \\
\text { presentation }\end{array}$ & $\begin{array}{l}\text { Total no of } \\
\text { exposure days }\end{array}$ \\
\hline $14-15$ & 1 year & 19 \\
\hline $13-15$ & 18 month & 49 \\
\hline $10-12$ & Since birth & 40 \\
\hline $13-14$ & 9 month & 30 \\
\hline $12-13$ & 1 year & 31 \\
\hline
\end{tabular}

Table 3 shows that $80 \%$ cases had their 1 st presentation in their infancy and all patients who developed inhibitor had $<50$ exposure days. None of patients, who had more than 50 exposure days, develop inhibitor. Duration of exposure was 0-25 exposure days in 27 patients followed by $26-50$ in 14 patients, $51-75$ in 6 patients, 76-100 in 4 patients, $101-125$ in 2 patients, $>125$ in 1 patients (Table 3).

Table 4: Coagulation profile of inhibitor positive patients.

\begin{tabular}{|lllll|}
\hline $\begin{array}{l}\text { Age } \\
\text { (yrs) }\end{array}$ & $\begin{array}{l}\text { aPTT } \\
\text { (control) } \\
\text { sec. }\end{array}$ & $\begin{array}{l}\text { aPTT } \\
\text { (Test) } \\
\text { sec. }\end{array}$ & $\begin{array}{l}\text { F VIII } \\
\text { level } \\
(\%)\end{array}$ & $\begin{array}{l}\text { Inhibitor } \\
\text { titer } \\
\text { (BU/ml) }\end{array}$ \\
\hline 10 & 32.7 & 141.4 & $<1$ & 17.2 \\
\hline 13 & 30.1 & 126.6 & $<1$ & 3.0 \\
\hline 14 & 30.1 & 111.1 & $<1$ & 3.025 \\
\hline 8 & 30.1 & 102.6 & $<1$ & 3.5 \\
\hline 14 & 28.0 & 104.3 & $<1$ & 4 \\
\hline
\end{tabular}

There were maximum number (4 patients) positive for inhibitor in 26-50 exposure days group (4/14; 28.5\%). 1 positive in 0-25 exposure days group and none other group develops inhibitor $(1 / 27 ; 3.7 \%)$. In our study association between number of exposure days and development of inhibitor does not follow any particular trend.

Two patients were expired due to intracranial haemorrhage $(2 / 54 ; 3.7 \%)$. No record about inhibitor development was available in these patients.

Table 4 show that all of inhibitor positive cases were of severe hemophilia. 4 cases $(80 \%)$ were low responders and 1 case was high responder (20\%).
In 1 st group ( 0 - 25 exposure days) inhibitor titre was 17.2 $\mathrm{BU} / \mathrm{ml}$ and in second group (26 - 50 exposure days) the mean value of inhibitor titre was $3.38+/-0.47 \mathrm{BU} / \mathrm{ml}$.

Out of 54 patients 49 patients were of Hemophilia A and 5 were of Hemophilia B. All these patients were of severe Hemophilia (factor activity $<1 \%$ ) inhibitors were developed in 5 patients of Hemophilia A having a prevalence of $10.2 \%$, no patient of Hemophilia B develop inhibitor (Table 4).

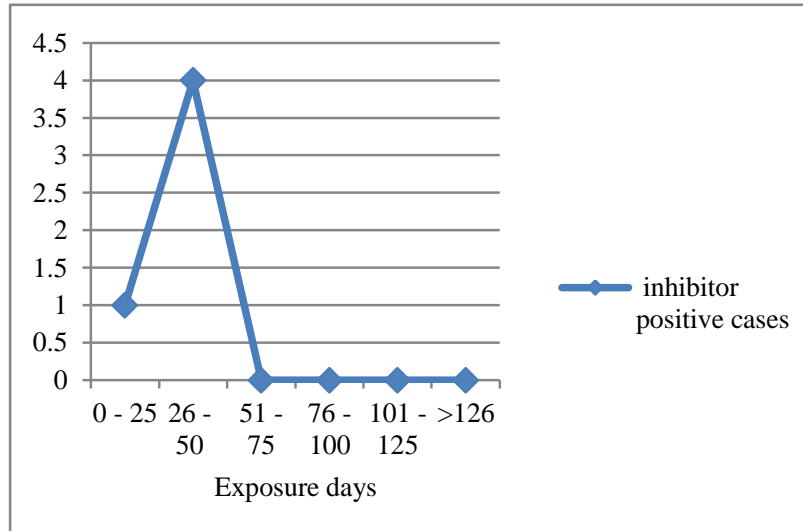

Figure 1: Relation of inhibitor positive cases with exposure days.

Patient from 0-25 exposure days group was high responder (inhibitor level 17.2 BU) and in 26-50 exposure days group four patients develop inhibitor having mean value $3.38 \mathrm{BU}+/-0.47$. All patients in this group were low responders. Out of these five inhibitor positive patients, four patients had their first exposure to factor concentrate in their infancy and one patient had exposure at age of 18 months (Figure 1).

\section{DISCUSSION}

Hemophilia an X linked hereditary bleeding disorder, leading to deficiency of factor VIII (FVIII) or factor IX (FIX). Most effective and easily available treatment available is specific factor replacement therapy. Development of inhibitor antibody is most important complication associated with treatment leading to decreased effectiveness of treatment and increased cost of treatment which of major concern in developing countries like India. There is paucity of data available in our country. Keeping these facts in mind this study was conducted.

In our study we observed that mean age for inhibitor development was 11.8 year (range 8-14 year) as compared to other studies conducted in India having mean age of 17.7 year. ${ }^{6}$ It was observed during study that development of inhibitors also affected by number of exposure days. In our study we concluded that patients develop inhibitors after mean 33.8 exposure days (range 19-49 exposure days). These findings are coincides with other studies done previously. In one study conducted in 
India inhibitors was developed after a mean 47.5 (range 17 - 98) exposure days. ${ }^{6}$ Another study conducted in western world also resulted in same findings but these findings differ from a study conducted in India which states that it is expected that patients will develop inhibitors within 10-15 exposure days. ${ }^{7,8}$

In our study we observed that $80 \%$ patients who develop inhibitor had $1^{\text {st }}$ exposure in their infancy. This finding is similar to other study done in other part of world. ${ }^{9}$

In our study we used recombinant factor concentrates for treatment of patients. In this study prevalence of inhibitors was $10.2 \%$ in severe Hemophilia A patients, none of Hemophilia B patient developed inhibitor but considering small sample size we can't comment about inhibitor development in this group. Prevalence of inhibitors is less in our country as compared to western studies. Findings from Indian studies show prevalence of inhibitors ranging from $5.1 \%$ to $13 \%$ in different studies. ${ }^{6,8,10}$ Studies from other parts of world shows a higher prevalence ranging from $24-30 \%$. $^{6,9,11,12}$

Keeping these facts in mind it is necessary to identify patients with inhibitors and provide treatment facilities to them so these patients can lead a productive life because management of Hemophilia patients with inhibitor is very difficult.

In this study sample size was small so before reaching a final conclusion we need a study done on large group. Some studies mentioned that genetic factors also play a role in development of inhibitors this part was lacking in our study. ${ }^{8}$ We recommend that genetic factors should also be considered in future studies.

Funding: No funding sources

Conflict of interest: None declared

Ethical approval: The study was approved by the Institutional Ethics Committee

\section{REFERENCES}

1. Kliegman RM, Stanton BF, GemeIII JWS, Schor NF, Behrman. Nelson textbook of pediatrics 19th edition. 2011. p. 1699-1702.

2. Witmer C and Young G. Factor VIII inhibitors in Hemophilia A: rationale and latest evidence.Ther Adv Hematol. 2013;4(1):59-72.

3. Jarres. Current Controversies in the Formation and Treatment of Alloantibodies to Factor VIII in Congenital Hemophilia A. ASH Education Book. December 10, 2011. Pp. 407-412.

4. Mathews V, Nair SC, David S. Semin Thromb Hemost. 2009;35(8):820-6.

5. Franchini M, Mannucci PM. Past, present and future of Hemophilia: a narrative review. Orphanet J Rare Dis. 2012;7:24.

6. Ghosh K, Shetty S, Kulkarni B. Development of inhibitors in patients with Hemophilia from India. Hemophilia. 2001;7(3):273-8.

7. Kreuz W, Ettingshausen CE, Auerswald G. GTH PUP Study Group. Epidemiology of inhibitors and current treatment strategies. Haematologica. 2003;88(6):EREP04.

8. Phadke S. Hemophilia Care in India: A Review and Experience from a Tertiary Care Centre in Uttar Pradesh. Indian J Hematol Blood Transfus. 2011;27(3):121-6.

9. Gouw SC, Bom JG, Berg HM. Treatment-related risk factors of inhibitor development in previously untreated patients with Hemophilia A: the CANAL cohort study. Blood. 2007;109(11):4648-54.

10. Dubey A, Verma A, Elhence P. Evaluation of transfusion-related complications along with estimation of inhibitors in patients with Hemophilia. A pilot study from a single center. 2013;7(1):8-10.

11. Astermark J. Immune tolerance induction in patients with Hemophilia A. Thromb Res. 2011;127(Suppl 1):S6-9.

12. Eshghi P, Mahdavi-Mazdeh M, Karimi M. Hemophilia in the developing count. ries: the Iranian experience. Arch Med Sci. 2010;6(1):83-9.

Cite this article as: Sharma RS, Arya AK, Rao YK. Clinico-epidemiological profile of hemophilia with special reference to development of inhibitors in Indian scenario: a crosses sectional study at tertiary care centre in north India. Int J Contemp Pediatr 2016;3:922-5. 